\title{
Clinical essentialising: a qualitative study of doctors' medical and moral practice
}

\author{
Kari Milch Agledahl • Reidun Førde • \\ Åge Wifstad
}

Published online: 25 March 2010

(c) The Author(s) 2010. This article is published with open access at Springerlink.com

\begin{abstract}
While certain substantial moral dilemmas in health care have been given much attention, like abortion, euthanasia or gene testing, doctors rarely reflect on the moral implications of their daily clinical work. Yet, with its aim to help patients and relieve suffering, medicine is replete with moral decisions. In this qualitative study we analyse how doctors handle the moral aspects of everyday clinical practice. About one hundred consultations were observed, and interviews conducted with fifteen clinical doctors from different practices. It turned out that the doctors' approach to clinical cases followed a rather strict pattern across specialities, which implied transforming patients' diverse concerns into specific medical questions through a process of 'essentialising': Doctors broke the patient's story down, concretised the patient's complaints and categorised the symptoms into a medical sense. Patients' existential meanings were removed, and the focus placed on the patients' functioning. By essentialising, doctors were able to handle a complex and ambiguous reality, and establish a medically relevant problem. However, the process involved a moral as well as a practical simplification. Overlooking existential meanings and focusing on purely functional aspects of patients was an
\end{abstract}

K. M. Agledahl ( $\square)$

Finnmark Hospital Trust, Sykehusveien 35,

9613 Hammerfest, Norway

e-mail: Kari.Agledahl@helse-finnmark.no

R. Førde

Section for Medical Ethics, University of Oslo,

P.O. Box 1130, Blindern, 0318 Oslo, Norway

A. Wifstad

Institute of Community Medicine, Faculty of Medicine,

University of Troms $\varnothing, 9037$ Tromso, Norway integral part of clinical practice and not an individual flaw. The study thus questions the value of addressing doctors' conscious moral evaluations. Yet doctors should be aware that their daily clinical work systematically emphasises beneficence at the expense of others-that might be more important to the patient.

Keywords Beneficence - Clinical decision-making · Dehumanising - Empirical research · Grounded theory . Medical ethics - Moral practice · Professional values . Qualitative

\section{Introduction}

The ideal of being a good doctor is a powerful one for most clinicians. ${ }^{1}$ This involves not only technical skills, but also an ability to attend to the moral demands of the profession. Clinical medicine aims to relieve patients' suffering and improve their health, so every medical action has a moral dimension (Pellegrino 2001; Carrese and Sugarman 2006). Still, doctors rarely discuss ethical issues. Many doctors perceive modern bioethics as alienating and of little relevance to regular clinical work (Davies and Hudson 1999; Førde et al. 1997). How can moral issues be so abundant in clinical practice, yet so absent in medical discourse?

Recent empirical studies exploring the moral experience of doctors mainly rely on interviews with doctors who recount their own experience of moral problems (Holm 1997; Arnman 2004; Kälvemark et al. 2004; BraunackMayer 2001). These studies can, however, only address the physicians' conscious moral reasoning which may not

\footnotetext{
${ }^{1}$ See for instance BMJ's September 2002 issue: "What's a good doctor and how do you make one?" 2002 Sep 28;325(7366).
} 
accord with their real actions. The studies are also limited to what doctors themselves define as moral problems, yet the ethical aspects of medicine often remain tacit in practical work, and so are difficult to reveal in an interview.

Some ethicists have suggested that doctors have poor moral perception (Casarett 1999), whereas others have brought up the inclination of doctors to express moral judgements as medical ones (Sayers and Perera 2002). Another possibility is that doctors' moral judgements are integrated in their medical judgements and therefore not explicit. These proposals do not answer how doctors deal with the specific moral parts of clinical medicine, but it indicates that in order to establish doctors' moral judgements, we must also address their medical judgements. In our study we have therefore examined doctors' clinical work in order to reveal how the moral aspects of their practice are handled.

\section{Method}

We wanted to maximise the diversity of the data by including doctors from different specialities, of both sexes, and with varying age and experience. Over one hundred hours of observation were conducted, including patient consultations, ward rounds and various internal meetings. In addition, interviews ranging from 20 to $60 \mathrm{~min}$ were carried out with each participating doctor. In all 15 doctors were observed and interviewed (by KMA): six general practitioners, three surgeons and six internists from different practices and hospitals. Six general practitioners were contacted directly by KMA (two of them declined participation because of little patient contact), and two were contacted by a participating GP. Each hospital department was contacted via the department manager, and the surgeons and the internists were recruited by the department manager or by KMA. None of the hospital doctors declined participation. All doctors and patients were made aware of the study, and informed consent was obtained from participating doctors and patients in direct contact with the observed doctors. About $10 \%$ of the patients in general practice and less than $5 \%$ of the patients in the hospital setting declined participation. The Regional Committee for Medical Research Ethics approved the study, and the Directorate of Health granted dispensation from confidentiality.

The data were collected and analysed using grounded theory (Glaser and Strauss 1967; Glaser 1978). Each doctor was observed over a full working day, including internal meetings, sitting rounds, ward rounds, and consultations with patients. We did not limit data collection to cases where the moral aspects of medicine were evident, such as intensive care units, requests for abortion or care for dying patients. While such cases also were represented in the study, we wished to include the more tacit moral aspects integrated in every day medicine, as the notion that all clinical medicine has a moral dimension was a central premise of the study. In accordance with the method, the field was first approached without any clear theory or distinct research question. The observer (KMA) aimed to stay open to what was happening in the field, and to what were the participants main concerns, all the time comparing similarities and dissimilarities in the doctors' clinical approaches. Especially noted was the doctors' line of reasoning, value-laden expressions, elements of conflict between participants, surprising events, or just a feeling that "something is going on". As the analysis proceeded the observer aimed to test and elaborate emerging categories more specifically.

An interview was conducted with the observed doctor immediately after each observation day. In one instance the interview was done the day after observation. The interviews were semi-structured and focused on clinical situations that had occurred during the working day. After a small enquiry about how the doctor felt about the observation, the interview continued with questions like: "Were there any patients or situations today, which you found especially demanding?" Subsequent questions explored the doctors' intentions and thoughts about a specific patient or their concrete practice. The interviews also presented an opportunity to pick up on aspects the observer could have failed to notice. Moral expressions and evaluating statements were intentionally avoided. At the end of the interviews, participants were invited to a more evaluative discourse with questions like: "What was your aim as a doctor in this specific consultation?" or "Have you done anything today that made you feel like a good doctor?" To minimise disturbance by the researcher, data was gathered by taking field notes immediately after the observations and interviews. This is also in line with the analytical method used, as redundancy of little relevant data is to be avoided. The field notes described participants' uttering and actions, as well as the context of the observed situations.

The observation and interview notes were first coded incident by incident, while constantly comparing the incidents with each other and with emerging concepts. As certain concepts constantly appeared in the data, further analysis followed these central issues together with a more selective coding. NVivo7 software was used to organize the codes and the emerging categories. General practitioners were first included, and after a preliminary analysis a medical and a surgical department were chosen in an effort to modify and deepen the emerging concepts. This theoretical sampling was done in several cycles, and analysis was constantly ongoing with data collection. KMA gathered and coded all data, and the analysis was constantly 
discussed and re-examined by all authors. ${ }^{2}$ Preliminary results were also presented and discussed with a group of clinical physicians to enhance validity. Data collection continued until the emerging theoretical concepts had reached saturation level, and no further observations and interviews brought up any new significant information about the central concepts and their interrelationship. The constant comparative analysis employed in this research is hermeneutical in that it requires a constant shift between empirical gathering of data and formulation of theoretical concepts, which again are constantly modified by new empirical data. As a result, the study is not an empirical collection and summary of data, but an attempt to gain theoretical insight into the field. The aim of the analysis is to generate conceptual categories that can account for much of the doctors' behaviour. These categories and their interrelations form the substantial theory here presented.

\section{Results}

As intended, there was considerable diversity among patients, clinical problems, professional environments, and doctors' personalities. Despite these differences, it soon became clear that the doctors approached the clinical situation basically the same way. Irrespective of the problem presented, the doctors struggled to handle each particular problem within the limits of medicine, and this shaped their approach to patients and clinical cases. Their mutual way of handling clinical issues was best understood as a process we have called 'essentialising'.

Essentialising roughly consisted of deconstructing the situation at hand and the patients' concerns, and reconstructing selected elements into a specific clinical problem. Through this reconstruction of the clinical problem, it became possible to handle the problem within the scope of biomedicine. Essentialising was a way of addressing the complexity of a practical case and come out with a defined clinical problem. The process consisted of several interrelated, but distinct, ways to modify and direct the problem at hand. These were not explicit actions, but altogether common and ever recurring parts of their clinical practice.

\section{Break down}

A distinct feature of the doctors' clinical approach was break down of the situation or patient information. Doctors split the situation into smaller units for easier systematisation of

\footnotetext{
2 The main author (KMA) also participated in two consecutive Grounded Theory seminars (London 2006 and 2007) hosted by The Grounded Theory Institute, where some of the data and the emerging theory was presented to and discussed with Dr. Barney Glaser, one of the founder of this methodology.
}

the situation. The patients could present vague symptoms or complex medical problems with other enmeshed anxieties. To handle such compound enquiries, the doctors broke the problem down into smaller, more manageable parts. By doing this it was possible to address each component of the problem separately:

A female patient enters the practitioners' office, seems stressed and talks fast in broken Norwegian. She sinks into a chair. Patient: "I' $m$ so ill; I do not have the energy to do anything. My neck hurts, I'm freezing, I'm weak, I have to do an assignment, but this is not working out..." Doctor: "Your neck hurts?" Patient: "Yes, my throat is soar and I'm aching here [pointing at the side of her neck]. I always get a soar throat, maybe every month. I thought I should have an operation..." Doctor: "Does it hurt anywhere else?" Patient: "Yes, my back hurts. And my chest. And my legs are hurting a bit too." Doctor: "A little bit of everywhere, I gather? Do you have fever?" Patient: "Yes." Doctor: "Have you measured your temperature?" Patient: "No, I do not have a thermometer." Doctor: "Then you must get hold of one! Do you have fever now?" Patient: "No, I don't think so." [Feels her forehead] Doctor: "Do you have a cough?". (Doctor 10)

In order to better understand the patient's vague illness, the doctor breaks down the clinical situation into concrete questions that the patient is able to answer.

Although the patients often presented the problems through the use of continuous and narrative stories, the doctors were not concerned with the narrative, and interrupted to fragment the patients' stories so that they could obtain the medically relevant information:

The patient sighs heavily as she sits down. Patient: Well, now it has got to the other shoulder! She pats her right shoulder. Doctor: What do you do for a living? Patient: I work in the home nursing care. Doctor: As...? Patient: An enrolled nurse. Doctor: Yes. It is hard work? Patient: No, not especially. It was worse back when I was working at the nursing home, then you just had to take whatever turned up. You know, I had to change my workplace when the trouble started in my other shoulder... Doctor [takes a look at his computer]: Then you were on sick leave for two years? Patient: Yes, and now it has got to my other shoulder... Doctor: Yes. What do you want me to do for you then? (Doctor 13)

We here sense that the patient wants to tell the story of her former work, how her shoulder afflictions made her quit her job, and her anxieties about it now reoccurring. The doctor, however, wants to cut the story short and pay attention to the facts necessary for intervention. 


\section{Concretising}

Another aspect of the doctors' clinical approach was concretising the situation and the patients' complaints. When doctors discussed cases with colleagues, they stressed often visible or measurable aspects such as blood pressure, blood tests, radiographs, and clinical findings:

Doctor I: She has been admitted for rehabilitation. She is poorly mobilised and nourished, and she is low in albumin. Nurse: Is she the one with the black toes? Doctor II: They are not black; they are poorly circulated. Doctor I: We have to at least mobilise her into a chair. Doctor II: She also has diarrhoea and a positive Hemofec. It is somewhat hard to interpret. But judging her blood values, everything looks better. (Doctor 6 and colleague)

This patient is no clear-cut medical case, but the doctors are defining the problem in terms of concrete bodily functions and test results.

Patients were also asked to point out the precise location of their problem, to quantify their pain, and to specify their worries. Concretising was used as a means of clarifying what the patient was actually talking about. Bodily experiences are of such a private nature that it can often be difficult to establish what a particular patient means when describing a sensation. Concretising was a way in which doctors could objectify the patients' descriptions and thus reach mutual understanding of the problem:

A consultant talks to an elderly male patient during rounds: "How much pain are you in?" Patient: "Well ..." Consultant: "Is it any better now than when you arrived, or is it just as painful?" Patient: "Well ... It is what it is ... sometimes better, sometimes worse." Consultant: "Sometimes better and sometimes worse, eh?" Patient: "It's worse when I stand still. It's somewhat better to walk a little." Consultant: "Indeed? When you walked over here from your room, how much did it hurt? On a scale from 1 to 10?" Patient: "2." Consultant: "How far could you walk then?" Patient: "To the kiosk." Consultant: "Did you walk all the way to the kiosk upstairs? How painful was that, on a scale from 1 to 10?" (Doctor 9)

The patient is very vague about his afflictions, so to establish whether or not the treatment has been beneficial, the doctor is forcing him to state a precise level of pain and distance of walking.

\section{Categorising}

A third part of the doctors' clinical approach was categorising the information. When patients described an affliction, doctors placed it into an appropriate medical category. In this way patients' feelings and statements were categorised as distinct medical symptoms, which could then be entered into the medical record:

Interviewer: "Your first patient today mentioned that she had discomfort in her chest. What were your thoughts about that?" Doctor: "She brought it up somewhat late in the consultation and I was beginning to run out of time. It didn't sound that serious, and it wasn't anything acute, she had had it for several years. I could have taken a spirometry of course... Most likely it is muscular, she is sitting quite tense, like this." [Shows her posture] (Doctor 3)

Although the doctor had ignored the patient's expressions of chest discomfort in the consultation, he had actually noticed her complaint. Because of the circumstances of the case, the medical history, the patient posture and the timing in the consultation, he categorised the complaint as nothing serious, likely muscular-and not in need of medical attention.

When the doctors examined their patients, they defined their results as medically normal or abnormal in a definite way, thus categorising their own observations as distinct medical findings:

A resident confers with the attending physician about a middle-aged female patient. Attending: "Where is her pain situated?" Resident: "She has pain everywhere!" Attending: "Does it hurt when you touches her nose? [Laughs] I'm exaggerating, but it's important to check if the patient expresses pain wherever you touch her, because then it reflects something else." (Doctor 4)

The resident has examined the patient and found that her whole body is hurting, and he does not know how to deal with such an extensive pain. The attending insinuates that the resident has just described the patient's expressions, and not categorised it into a clinical finding. He implies that if the patient utters pain during the whole examination, it should not be categorised as medically relevant pain.

\section{Existential filtering}

Breaking down, concretising and categorising can be seen as purely practical ways of addressing a complex reality, but essentialising also entailed ways of handling the more value-laden aspects of the situation. In an effort to direct their focus of attention, the doctors undertook an existential filtering. When approaching a case or a patient, the doctors systematically ignored the more existential meaning in order to direct the medical issue. The problems were faced 
at a practical level in order to reach the functional elements that the doctors could do something about:

An elderly female patient is discussed at sitting rounds. Doctor: "We have discontinued treatment on this patient. How is she?" Nurse: "She is getting worse. She does not want any care and pushes us away." Doctor: "Her CRP-level is about to explode! You have to take her temperature." Nurse: "But is she going to have any medication? We are not able to give her anything to swallow anyhow." Doctor: "No, she will not have any; we have discontinued her treatment." Nurse: "But in that case you have to record it on the medical chart, because she has been given medication these last 24 hours." Doctor: "Precisely. Well, then I will withdraw this: Antibiotics, anti-coagulation..." (Doctor 1)

The situation is obviously existential for this patient, who is about to die, but the medical discussion does not evolve around the patient's anticipated death. Instead, they discuss test results, medication, and practical issues concerning chart registration.

Existential filtering took the focus away from the patients' private feelings and what the suffering meant to the particular patient. The subjective meaning of the condition was not addressed by the doctors, and sometimes even actively suppressed:

A disconsolate patient who had recently had an extra uterine pregnancy explains that her husband recently told her that he had developed a Chlamydia infection. She is crying. Patient: "And now I do not know if this could have caused my extra uterine pregnancy!" The doctor does not answer this question. Doctor: "But did you not take a Chlamydia test while you were pregnant?" Patient: "No ... I don't know." Doctor: "It is one of the standard tests." He looks in her record. Patient: "This other doctor went so far as to imply that my husband had been cheating on me. He said that anything else would be very unlikely." Doctor: "I'm sorry he was so determined. There are two alternatives: one is that you have had a latent infection, or else he has infected you. You talk to your husband, and I will call the microbiologist to get hold of your test results from the pregnancy." (Doctor 15)

Here, the underlying issue is of utmost importance to the patient: Is her husband cheating on her? Although aware of it, the doctor does not address this question directly. This existential aspect of the clinical issue is left to the patient, and the doctor limits his effort to the practical question of whether or not this is a newly acquired infection or a reactivation of an earlier one.
Functional focus

While existential filtering divested the case of certain values, others were accentuated. Through their functional focus, the doctors draw the focus of attention to the patients' physical and mental function. Irrespective of how a problem was presented, the aim was understood in terms of improving the patient's functional abilities:

A terminal cancer patient is discussed during sitting rounds: Nurse: "She wants to go home." Doctor: "Yes, I have spoken to her regular doctor about how we should handle her. She has these reconstruction plans for her house in preparation for returning home. We cannot tell her too brutally. We cannot demolish her psychological defences. She became aggressive once when we tried to address her unrealistic arrangements. At the same time she knows how serious this is. It is a psychological defence, and the only thing preventing deep depression. So we must allow her that." (Doctor 6)

The patient does not seem to be aware of the gravity of her own illness, and the staff is struggling with how much of the truth to reveal. The doctor phrases this into a question of what will benefit the patient's psychological function.

The functional focus was implicitly present in most of the doctors' clinical practice, and in many instances they also explicitly defined the motivation for their actions in terms of benefiting the patient's function:

Doctor: "We had an elderly lady here last month with lots of different somatic problems, and she was confused too. She was referred to different departments around the hospital, and every department only cared about their little detached parts, fixed it and sent her home. And she kept coming back to the doctor. Last time, she was having surgery in her bladder, but they postponed it. She was kept fasting for days - an elderly woman with such tiny reserves! If we could fix her somatic problems and calmed the environments around her, I'm sure she could function a lot better." (Doctor 12)

The doctor rejects the fragmented treatment of this elderly patient, not because he considers it dehumanising to the patient, but because a different approach would benefit her functional level.

The elements here presented describe different aspects of essentialising, but are fundamentally interrelated, and often occurred simultaneously in a single encounter or case discussion. Breaking down and concretising the patient's complaints could enhance the existential filtering of a case, and categorising the problem in medical terms often involved a functional focus. 
Essentialising is not an explicit method, but a theoretical concept that describes doctors' clinical work in a useful way. It reveals some of the difficulties of clinical work, and what the doctors' are striving to come to terms with in each particular case. Essentialising describes doctors' practical manner of handling multifaceted and often ambiguous clinical situations in a medical way. By systematically reframing the problems into questions that could be answered within the medical framework, they sought to pinpoint those elements of the patients' suffering that they could do something about. In addition to being a practical method of deconstructing a complex reality, it was also a way of establishing the purpose-or essence-of clinical intervention.

\section{Discussion}

With this small exploratory study we have tried to provide a new perspective on doctors' moral practice in daily clinical work. Despite the fairly small number of informants, the number of clinical situations was large and varied. The substantial theory generated from these clinical situations is therefore intended to be transferable to other clinical situations, and a helpful starting point for further studies on clinical work (Malterud 2001). The theory gains its credibility from the clear empirical foundation, the recognition of the concepts by clinicians and that the theory is valuable for understanding the practice (Wilson and Hutchinson 1991). As the main researcher (KMA) is herself a doctor, some well known dangers in doing research on one's own profession has to be carefully considered (Wadel 1991). On the other hand, being a doctor helped the researcher to gain access to the clinical situations and to understand the doctors' medical terminology and actions, and probably minimised the intrusion of daily practice.

Sociology studies of doctors' clinical decision-making have shown that their decisions are not mere calculation of medical facts, but that doctors actively shape the clinical problem (McKinlay et al. 1996; Luftey et al. 2008). This is consistent with our findings, although our theory of essentialising also addresses the moral aspects of clinical practice. The process of essentialising simplified the situations both practically and morally. Patients' private values were disregarded as the doctors persistently focused on what they could do for the patients' physical and mental functions. In this way essentialising was founded on a moral responsibility to do the best for the patients' health. Although implicit, their clinical practice constantly emphasised the moral value of beneficence. Thus, the doctors' medical decisions could not be separated from their moral decisions, as beneficence constituted a moral base for their medical actions Beneficence is used here in a broad sense, as the doctors were concerned about improving their patients' health, both by preventing harm and promoting health. ${ }^{3}$ Other empirical studies have found beneficence to be a principal moral consideration of doctors (McGuire et al. 2005; Blondeau et al. 1998), although the doctors in our study were primarily concerned with patients' function, rather than the best possibilities for all aspects of patients' lives.

The tendency of medicine to dehumanise patients has long been debated and criticised (Cassell 1991). Danger occurs when doctors filter out the personal experience of suffering, and patients' feeling of being dehumanised exacerbates their distress rather than relieving it (Daneault et al. 2006). Despite doctors' good intentions, they risk harming instead of helping these patients. In our study we do find that doctors systematically overlook the private experience of patients, which may indeed leave the patients feeling objectified. But what our study adds is that this process is not done because doctors fail to see patients as people, but as a moral imperative of benefiting the patients. Essentialising is not a move away from moral values, but a shift where the value of beneficence is emphasised.

Our study indicates that filtering of existential values is not a shortcoming of individual doctors, but a product of their systematic clinical approach. Likewise, the emphasis on beneficence does not result from doctors' personal beliefs, but is an integral part of clinical practice-part of the process of essentialising. A request for more ethics education would not solve the problem because it is not a question of doctors lacking ethical knowledge, and, as we have shown, the process of essentialising is in fact morally motivated. Demands for a more caring and holistic medicine would not be consistent with doctors' need to essentialise the clinical problem. With its focus on human functions, medical knowledge demarcates what doctors can deal with professionally. It remains an open question whether medicine can actually address the more existential aspects of suffering.

Nevertheless, doctors and their patients should be aware that clinical practice tends to take only a single moral consideration into account-benefiting patients' physical and mental function. Other moral values are largely disregarded in the process of essentialising. If there is a message for patients from this study, it is that, if you feel objectivated by your doctor, he probably does it with the

\footnotetext{
${ }^{3}$ In this study we do not distinguish between beneficence and nonmaleficence, as frequently done (Beauchamp and Childress 1979), because we find no clear evidence in the data for making this distinction. In line with the intentions of Grounded Theory not to rely on predefined categories, we only use conceptions that emerge as relevant from the data. In our observations, doctors did not distinguish between preventing harm and promoting good for the patients' health, and so this distinction was considered superfluous for the purpose of describing their practice.
} 
best intentions. And the moral lesson for doctors is that, even if your clinically sound decision is morally motivated, it may not necessarily be the morally good thing to do.

Acknowledgements We would like to thank all participating doctors for their contributions, their respective departments and clinics for their hospitality, and all affected patients for their goodwill.

Open Access This article is distributed under the terms of the Creative Commons Attribution Noncommercial License which permits any noncommercial use, distribution, and reproduction in any medium, provided the original author(s) and source are credited.

\section{References}

Arnman, R. 2004. Doctor's experiences of work related moral problems: responsibility without clear boundaries. Doctoral dissertation, Karolinska University Press, Stockholm.

Beauchamp, T.L., and J. Childress. 1979. Principles of biomedical ethics. New York: University Press.

Blondeau, D., P. Valois, E.W. Keyserlingk, M. Hebert, and M. Lavoie. 1998. Comparison of patients' and health care professionals' attitudes towards advance directives. Journal of Medical Ethics 24: 328-335.

Braunack-Mayer, A.J. 2001. What makes a problem an ethical problem? An empirical perspective on the nature of ethical problems in general practice. Journal of Medical Ethics 27: 98103.

Carrese, J.A., and J. Sugarman. 2006. The inescapable relevance of bioethics for the practicing clinician. Chest 130: 1864-1872.

Casarett, D.J. 1999. Moral perception and the pursuit of medical philosophy. Theoretical Medicine and Bioethics 20: 125-139.

Cassell, E.J. 1991. The nature of suffering and the goals of medicine. New York: Oxford University Press.

Daneault, S., V. Lussier, S. Mongeau, E. Hudon, P. Paille, D. Dion, and L. Yelle. 2006. Primum non nocere: Could the health care system contribute to suffering? In-depth study from the perspective of terminally ill cancer patients. Canadian Family Physician 52: 1574-1575.
Davies, L., and L.D. Hudson. 1999. Why don't physicians use ethics consultation? Journal of Clinical Ethics 10: 116-125.

Førde, R., S. Lie, and O.G. Aasland. 1997. A course in medical ethics - a pain in the neck for the clinicians? Tidsskrift for Den norske legeforening 117: 1138-1140.

Glaser, B.G. 1978. Theoretical sensitivity: Advances in the methodology of grounded theory. Mill Valley, California: Sociology Press.

Glaser, B.G., and A.L. Strauss. 1967. The discovery of grounded theory: Strategies for qualitative research. Chicago: Aldine.

Holm, S. 1997. Ethical problems in clinical practice: The ethical reasoning of health care professionals. Manchester: University Press.

Kälvemark, S., A.T. Höglund, M.G. Hansson, P. Westerholm, and B. Arnetz. 2004. Living with conflicts-ethical dilemmas and moral distress in the health care system. Social Science and Medicine 58: $1075-1084$.

Luftey, K.E., S.M. Campbell, M.R. Renfrew, L.D. Marceau, M. Roland, and J.B. McKinlay. 2008. How are patient characteristics relevant for physicians' clinical decision making in diabetes? An analysis of qualitative results from a cross-national factorial experiment. Social Science and Medicine 67: 1391-1399.

Malterud, K. 2001. Qualitative research: Standards, challenges, and guidelines. Lancet 358: 483-488.

McGuire, A.L., L.B. McCullough, S.C. Weller, and S.N. Whitney. 2005. Missed expectations? Physicians' views of patients' participation in medical decision-making. Medical Care 43: 466-470.

McKinlay, J.B., D.A. Potter, and H.A. Feldman. 1996. Non-medical influences on medical decision-making. Social Science and Medicine 42: 769-776.

Pellegrino, E.D. 2001. The internal morality of clinical medicine: A paradigm for the ethics of the helping and healing professions. Journal of Medicine and Philosophy 26: 559-579.

Sayers, G.M., and S. Perera. 2002. Withholding life prolonging treatment, and self deception. Journal of Medical Ethics 28: $347-352$.

Wadel, C. 1991. Fieldwork in your own culture: An introduction to qualitatively oriented community research. Flekkefjord: SEEK.

Wilson, H.S., and S.A. Hutchinson. 1991. Triangulation of qualitative methods: Heideggerian Hermeneutics and grounded theory. Qualitative Health Research 1: 263-276. 